\title{
Combustion of Mechanoactivated Mixtures of Aluminum and Copper Oxide
}

\author{
Dolgoborodov Yu A*1,2,3,4, Yankovskii BD ${ }^{1}$, Kirilenko VG ${ }^{2}$, Streletskii AN ${ }^{2,3}$, Ananev SY ${ }^{1,3}$, Kolbanev IV ${ }^{2}$ and \\ Shevchenko $\mathrm{AA}^{2,4}$ \\ ${ }^{1}$ Join Institute for High Temperature RAS, Russia
}

${ }^{2}$ Semenov Institute of Chemical Physics RAS, Russia

${ }^{3}$ Moscow Institute of Physics and Technology, Russia

${ }^{4}$ National Research Nuclear University MEPHI, Russia

*Corresponding author: Dolgoborodov Yu A, Join Institute for High Temperature RAS, Semenov Institute of Chemical Physics RAS, Moscow Institute of Physics and Technology, Russia

Submission: 悳 October 26, 2018; Published: 眥 November 29, 2018

\begin{abstract}
The optimization of parameters of mechanoactivation of powder mixture of $\mathrm{Al}+\mathrm{CuO}$ for the purpose of realization of the most powerful energy release at chemical interaction of components was performed. Vibration and planetary type of the ball mills were used. The results of mechanoactivation on burning rate were controlled by means of high-speed photography of burning process of samples. Initiation of burning was carried out in the electro spark way with control of a current impulse. The non-stationary mode of propagation of chemical interaction of mixture components was recorded under low level spark. The influence of parameters of mixture porosity and current amplitude of a spark for induction period and the speed of distribution of the reaction front of was defined. Results of research indicate the prevalence of filtration nature of distribution of chemical interaction.

Keywords: Thermite mixtures; Mechanoactivation; Burning rate
\end{abstract}

\section{Introduction}

Thermite mixtures based on metals and solid oxidants allow to obtain a significant exothermic effect during combustion. $\mathrm{Al}+\mathrm{CuO}$ mixture allows receiving one of the highest exothermic effects per unit of volume (more than $20 \mathrm{~kJ} / \mathrm{cm}^{3}$ ). However, the burning rate of initial mixtures of micron powders usually does not exceed several tens of $\mathrm{mm} / \mathrm{s}$, which limits the field of their application. This is because that development of chemical reactions in solid mixtures takes place on the contact surface of reactants, which in the case of large particles is rather small. To increase this surface, various methods are used: ultrasonic mixing of nanosized powders, electrochemical deposition of submicron metal-oxidizer layers, etc. [1]. One of the relatively new methods for obtaining thermite composition is the preliminary mechanochemical activation of mixtures of micron-sized particles in high energy intensity ball mills. Initial components in this process are shredded, mixed and acquire new defects of crystal structure, which leads to an increase in the surface area of contact of the reagents at the submicron and nanoscale levels and also to formation of additional reaction spots. Thus, by means of mechanoactivation of oxidizer-metal mixtures it is possible to regulate the rate of energy release for different of specific application. In Russia, the method of preliminary mechanoactivation of solid oxidant-metal fuel mixtures has been actively used since the beginning of the 2000s [2-5], and the resulting materials are called Mechanically Activated Energetic Composites (MAEC).

The practical use of exothermic energy release is associated with the implementation of different parameters: the rate or power of heat release, the quality and intensity of light radiation, etc. However, in all cases, the completeness, or the effectiveness of the chemical interaction, is an important factor. This indicator, to a large extent, depends on the conditions of application: the physical parameters of the components, the initial parameters of the mixture, the energy and power of initiation, as well as other physical and geometric factors. In this work tendencies of manifestations of chemical interaction of $\mathrm{MAEC} \mathrm{Al} / \mathrm{CuO}$ are investigated under different conditions of its realization. An ultimate goal of a research is optimization of mechanoactivation parameters of this mixture for effective application in different conditions.

Before experiments the mixture of $\mathrm{Al}+\mathrm{CuO}$ powders were subjected to mechanoactivation. Then mixture was compacted in experimental samples with controlled porosity. Samples were mounted in experimental assemblies and initiation of chemical 
interaction was made. The characteristics of manifestations of combustion process of samples were an object of research in which mechanoactivation time, the samples porosity. The initiation parameters and the experiment scheme were parameters. As tools were used: high-speed camera, four-channel pyrometer, photoelectronic and electro contact sensors. The characteristics of a luminescence area were speeds of borders and brightness.

\section{The Materials and Mechanoactivation Parameters}

As the initial components, micron and nanosized powders were used. Al weight content was from 18 to $25 \%$. Mixing and activation was carried out in the vibration mill of the Aronov design or in the planetary mill "Activator-2sl» with steel drums and balls. Estimate of the energy intensity of the two types of mills based on the growth of the specific surface area of the test material $\left(\mathrm{MoO}_{3}\right)$ is for "Ativator-2sl" at a total power J=9.7W/g, and for the Aronov mill J=3.7W/g. Weight load of powders was 10-25g, the mass of balls was 200-300g. Hexane was added to reduce frictional heating. The starting powders and MAEC were analyzed by X-ray diffraction, electron microscopy and thermo-gravimetric analysis. It is established that as a result of activation the obtained material was a polydisperse mixture of fairly large conglomerates of flat fragments of $\mathrm{Al}$ particles $(\sim 1-10 \mu \mathrm{m})$ with submicron $\mathrm{CuO}$ particles. Owing to different strength characteristics of material, dispersion in sizes and a form of particles, conglomerates represented the disordered structures with numerous, but divided, points of contact of components. These points of contact of components, presumably, can serve as primary centers of chemical interaction.

\section{Experimental Results}

Primary analysis of mechanoactivation influence was carried out by means of determination of dependence between ignition delay time and mixture temperature. As a rule, the ignition delay increases with reduction of temperature. It was defined that temperature of ignition of the mixture, activated in different conditions, lies in range from 200 to $400{ }^{\circ} \mathrm{C}$. Ignition was carried out by a hot copper surface. The sample of the mixture weighing $35 \mathrm{mg}$ was dumped on the heated surface. The burning rates of the mixtures were measured in various metal, glass and plastic tubes. Figure 1 shows the dependences of the burning rate of $\mathrm{Al} / \mathrm{CuO}$
$18 / 82$ in a steel tube with a diameter of $10 \mathrm{~mm}$ on the activation time in a planetary mill. The density of the mixture was 0.3 of the maximum. With an increase in activation time, burning rate increases to maximum values of more than $450 \mathrm{~m} / \mathrm{s}$, and then begins to decrease, indicating that the mixture is overactivated and the components begin to react in the course of mechanical processing.

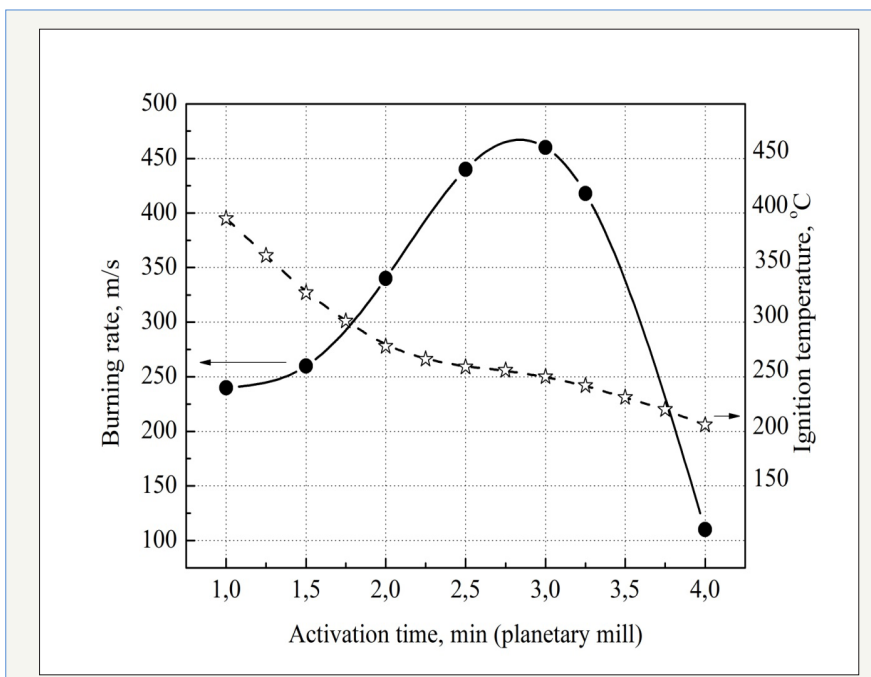

Figure 1: Burning rate and ignition temperature $\mathrm{Al} / \mathrm{CuO}$ $18 / 82$ vs activation time.

At electro spark initiation of a bulk sample on the horizontal plane (mass from $0,03 \mathrm{~g}$ and above) the area of a luminescence is formed. This area, on set of experimental data, should be characterized as the extending stream of the reacting clusters of mixture components in a cloud of the radiating plasma of burning products with a specific resistance of $10^{7} 0 \mathrm{~m}^{*} \mathrm{~mm}^{2} / \mathrm{m}$. By pyrometric measurements, the brightness temperature of a luminescence area changes from 2400 to $3700^{\circ} \mathrm{K}$ depending on mixture activation time. Characteristic scattering rate of burning products of local samples and also burning rate of linear samples (with a linear density from $0.2 \mathrm{~g} / \mathrm{cm}$ and above) are tens of meters per second. Existence of small air intervals between separated samples does not interfere with distribution of burning and does not influence burning rate. Increase in mass of separated samples leads to growth of expansion speed of chemical reaction.

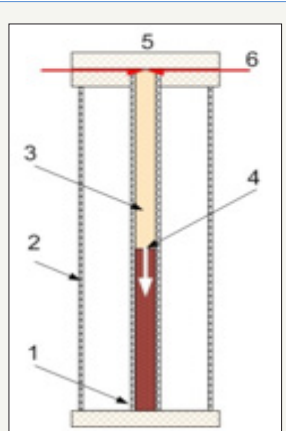

(a)
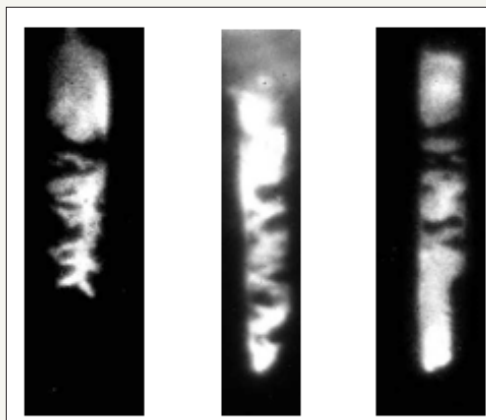

(b)

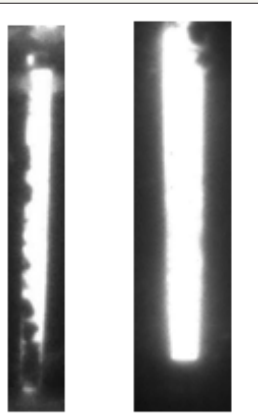

Figure 2: (a)Experimental scheme: 1-dark part of glass tube (no combustion), 2-glass vessel with water, 3-light part of tube (combustion), 4-a boundary between dark and light parts of tube, 5-spark gap, 6-electrodes; (b) Photos of luminescence inhomogeneity at various spark currents. The right picture- initiation with the maximum current through a spark interval. 
The burning initiation of the compacted mixture sample (porosity of 50-70\%) was carried out in the electro spark way in a glass tube with a diameter of $5.5 \mathrm{~mm}$ Figure 2 . The tube end face on the initiation side, as a rule, was closed. The spark gap between wire electrodes with a diameter of $0.1-0.5 \mathrm{~mm}$ was $0.1-1.0 \mathrm{~mm}$. Current through a spark interval was changed in the range of 40 $350 \mathrm{~A}$. The current impulse duration of a spark was $\sim 1 \mu$ s on the basis. The moment of sparking was used for synchronization of the high-speed photo recorder Cordin 222-224G. The photo recorder allowed to receive 16 photos of process in beforehand determined time points.

At photos a border between dark and light parts of a tube was fixed (Figure 2). This border was identified with some stage of chemical interaction characterized by a certain temperature. In case of the disordered structure of our mixture it may concern thermal explosion in the neighborhood of contact points of components. At small currents through an electric spark $(<150 \mathrm{~A})$ the area of burning has pronounced non-uniform character. Zones of a bright luminescence of hot products alternate with dark zones at photos. With increase in spark current the uniformity of a luminescence increases. Influence of mechanoactivation time: achievement of the maximum burning rate. Influence of a sample porosity (planetary mill): considerable reduction of induction period and increase in burning rate. Influence of spark current (vibration mill): considerable reduction of the induction period at insignificant reduction of burning rate (insufficient warming up of cold mix). Influence of length of a spark interval (planetary mill): minor changes in the induction period and increase in burning rate (increase in volume of an electro spark energy contribution)

The long luminescence abroad of the section of zones in process of its movement is caused by hashing and interaction of initially not contacting parts of components. Time interval between the moment of initiation and formation of border is usually called the induction period. Movement of this border in time was taken for the speed of burning of mixture in a tube. By set of experimental data is determined the tendency of change of characteristics of burning depending on parameters of mechanoactivation, compaction and initiation, Figure 3. Each tendency is created according to two experiments with identical other conditions. Analysis of dependences of Figure 3 reveals the strongest influence of mechanoactivation time, mixture porosity and a spark current amplitude for induction time and the rate of chemical interaction. It assumes the leading role of the filtration mechanism in energy transfer for initiation of chemical interaction in cold sites of mixture.

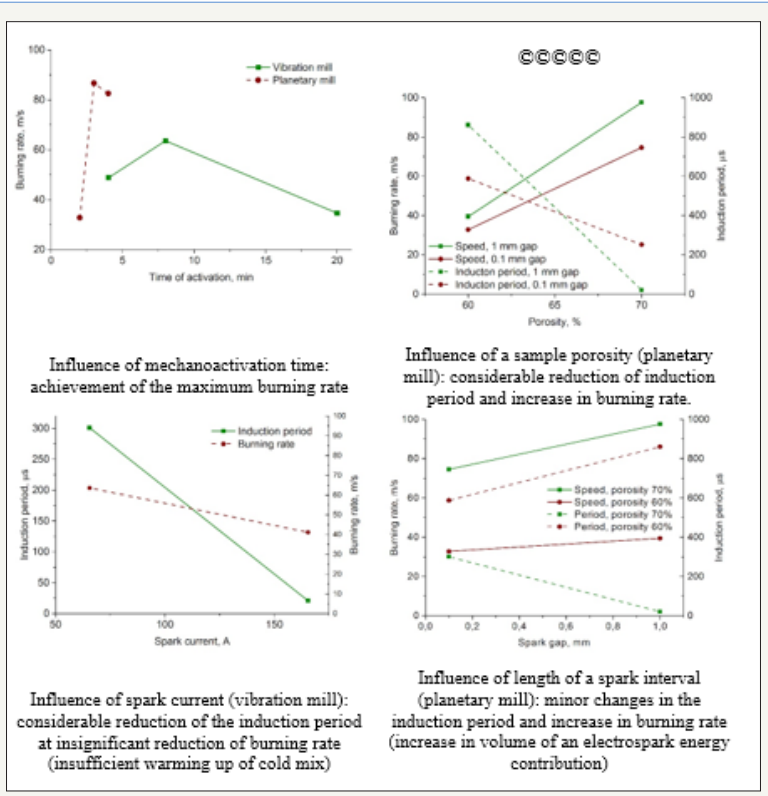

Figure 3: Set of experimental data.

\section{Conclusion}

In general, the results of the work have shown the promise of preliminary mechanochemical activation for the production of fastburning thermite compositions. For each type of mills there are optimum conditions of activation at which the greatest reactionary ability, rate and temperature of burning are reached. At excess of this value, there is a partial interaction of components in the activation process and decrease in burning characteristics.

\section{Acknowledgement}

This work was supported by the Russian Foundation for Basic Research (Grant No. 16-29-01030).

\section{References}

1. Zarko VE, Gromov A (2016) Energetic nanomaterials synthesis, characterization, and application. In: Zarko VE, Gromov A (Eds.), (1 edn), Elsevier Inc, USA. 
2. Yu Dolgoborodov A, Gogulya MF, Makhov MN (2002) Detonation like phenomena in $\mathrm{Al} / \mathrm{S}$ mixture. Proceedings Twenty-Ninth Intern. Pyrotechnics Seminar, USA, pp. 557-563.

3. Yu Dolgoborodov A, Makhov MN, Kolbanev IV, Streletskii AN (2004) Mechanically activated pyrotechnic composition, RF Patent No. 2235085.

4. Yu Dolgoborodov A (2015) Mechanically activated oxidizer-fuel energetic composites. Combustion, Explosion, and Shock Waves 51(1): 86-99.
5. Streletskii AN, Sivak MV, Yu Dolgoborodov A (2017) Nature of high reactivity of metal/solid oxidizer nanocomposites prepared by mechanoactivation: a review. J Mater Sci 52(20): 11810-11825.
Creative Commons Attribution 4.0

International License

For possible submissions Click Here

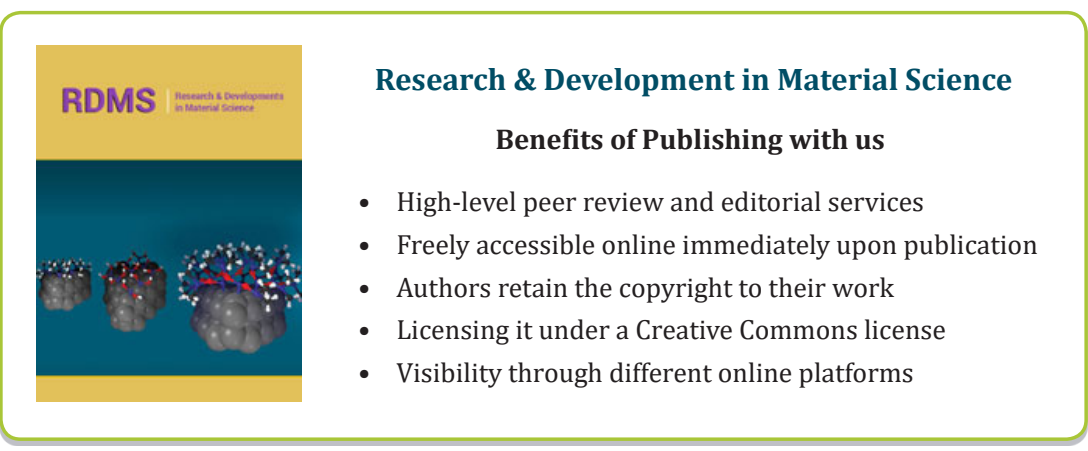

